ESTUDOS R:E?

\title{
A Filosofia da Educação na Rbep: o debate filosófico nos últimos 15 anos
}

Antônio Joaquim Severino

\section{Resumo}

Ao ensejo de analisar os trabalhos da área de Filosofia da Educação publicados nos últimos 15 anos nas páginas da Revista Brasileira de Estudos Pedagógicos (Rbep), o artigo busca explicitar a contribuição deles para o debate das questões educacionais de modo a evidenciar o lugar e a importância que o veículo atribuiu à análise filosófica no período. Procura identificar as temáticas e as preocupações centrais expressas pelos trabalhos divulgados, bem como as perspectivas dessas abordagens, ao mesmo tempo que propõe a discussão das tarefas que cabem à Filosofia da Educação e delineiam sua identidade e a especificidade de sua contribuição para o entendimento do sentido da educação tanto no âmbito teórico como na esfera prática. Argumenta então que, de uma perspectiva epistemológica, cabe-lhe elucidar as questões do conhecimento no campo educacional; de uma perspectiva axiológica, cabe-lhe explicitar os valores que sustentem a prática educativa; e, de uma perspectiva ontológica, cabe-lhe descrever a condição existencial do homem como pessoa e como ser histórico e social em processo permanente de autoconstrução.

Palavras-chave: Filosofia da Educação; prática educativa; ética; estética; política; epistemologia; antropologia. 


\section{Abstract}

The Education Philosophy at Revista Brasileira de Estudos Pedagógicos (Rbep): the philosophical debate in the past 15 years

With the purpose of analyzing the works done in the area of Philosophy of Education, published during the last 15 years in Revista Brasileira de Estudos Pedagógicos (Rbep), the essay aims to clarify their contribution in the discussion of educational issues in order to show the place and role assigned by this vehicle to the philosophical analysis during that period. It, then, tries to identify the main themes and concerns expressed by works published, as well as the prospects of these approaches, at the same time that it proposes the discussion of tasks that belong within the scope of the Philosophy of Education, tasks that outline their identity and the specificity of their contribution to the understanding the meaning of education, both at the theoretical and the practical spheres. It, then, argues that in an epistemological perspective, has to clarify the issues of knowledge in the educational field; from an axiological point of view, it has to make explicit the values that support the educational practice and, from an ontological perspective, it is responsible for describing the existential condition of man as a person and as an historical and social being under the ongoing process of self-construction.

Keywords: Philosophy of Education; educational practice; ethics; aesthetics; politics; epistemology; anthropology.

O que o filósofo é suscetível de propor são, por meio de reflexão sobre a própria ação de educar, os princípios que tornem possível essa ação e a ela lhe dão forma.

(Lévêque; Best, 1974, p. 97)

\section{Introdução}

A educação é prática de extrema relevância para a vida social. Na realidade, é poderosa e eficaz mediadora das práticas que viabilizam o existir histórico dos homens. Por isso, ela ocupa grande espaço de preocupações e cuidados por parte dos seus gestores, dos seus executores e dos que buscam explicitar os sentidos de sua efetivação.

Assim, uma revista de educação vinculada a um órgão público de gestão da educação nacional abre seu espaço para os estudiosos do 
fenômeno educacional sob todos os seus aspectos, daí o acolhimento que faz a trabalhos que expressam resultados de pesquisas no campo educacional, a apresentações de experiências bem-sucedidas, a propostas de condução das práticas gestionárias e docentes, a discussões sobre a política educacional, assim como sobre a legislação pertinente. E nesse grande espectro de debates não faltam aqueles cujo perfil se configura sob o modo filosófico.

Uma rápida consulta às páginas da Revista Brasileira de Estudos Pedagógicos (Rbep) é suficiente para se constatar que a Filosofia da Educação teve presença constante em seu projeto editorial; ao longo de seus 68 anos de trajetória, faz um significativo registro de toda a expressão da educação brasileira, sob todos os seus aspectos. A preocupação com os sentidos que a educação nacional assumiu durante essa caminhada sempre teve também sua tradução filosófica. Para se dar conta disso, basta apenas revisitar os títulos e autores dos trabalhos publicados.

À vista dessa constatação, mais que demonstrar a presença da Filosofia da Educação em suas páginas, o artigo se propõe a delinear de que modo a Filosofia da Educação manteve e manifestou essa presença nos últimos 15 anos, período tomado como recorte para este momento de análise e de comemoração.

Para tanto, buscarei traçar previamente um quadro teórico que permita sistematizar essa participação da Filosofia da Educação, montando um cenário em que se destacam as temáticas prevalecentes e os modos sob os quais a problematização específica se coloca nas coordenadas de um contexto histórico-social sempre em transformação.

\section{A existência humana tecida pela prática}

O existir histórico da humanidade realiza-se numa permanente malha de atividades de trabalho, de sociabilidade e de cultura. Vale dizer que trabalho, política e cultura simbólica tecem a existência concreta da espécie humana no seu dia a dia concreto. Tal existir se entrelaça cotidianamente com as práticas produtivas, mediante as quais os homens proveem sua subsistência retirando da natureza física os bens materiais imprescindíveis para a produção e a reprodução da vida, e com as práticas sociais, cuja mediação lhes permite assegurar uma intensa interação com seus semelhantes, gerando a vida social com seu intercâmbio de apoio mútuo igualmente imprescindível para a sobrevivência de todos. Entretece-se ainda com as práticas simbólicas, mediante as quais dão algum sentido a todas as coisas e situações de sua maneira de existir.

O que se vê então é que a existência histórica concreta dos homens é feita de uma complexa rede de práticas técnicas, políticas e culturais, que traduzem suas relações permanentes de troca com a natureza, com os seus semelhantes e com os produtos simbólicos de sua própria subjetividade. Os homens vivem então compartilhando os densos espaços dessas três esferas, intimamente articuladas entre si, vinculadas umas às outras. 
Mas, consideradas em si mesmas, essas práticas são sempre marcadas por grande ambiguidade, pois embora sejam as mediadoras substantivas do existir humano e, por isso, revelando-se necessárias para a realização da vida, elas são igualmente lugar da desumanização das pessoas... Assim, em que pese a relevância do trabalho para a plena realização humana, ele é continuamente lugar privilegiado de degradação do seu modo de ser. Seja por sua ausência, seja pelas condições deletérias em que venha a ocorrer, o trabalho pode degradar a condição existencial dos homens históricos e, assim, levar à sua despersonalização.

Do mesmo modo, quando se trata da vida social, ela tanto pode sustentar a plena realização humana dos indivíduos como pode igualmente, em determinadas situações, oprimir as pessoas, esvaziando-as da sua autonomia de sujeitos livres. É o que ocorre quando a relação interativa de troca se transforma em relação de dominação entre pessoas.

E, no caso das atividades simbólicas de produção e de fruição de cultura, elas podem comprometer seu papel doador de sentido a todas as demais dimensões do existir, deixando prevalecer significações alienadoras que fazem com que as pessoas percam sua própria identidade.

Assim, pelo trabalho, os homens estabelecem relações com a natureza material, em busca dos bens imprescindíveis para a produção e para a reprodução da vida. Mas essa atividade produtiva pressupõe a contribuição das outras duas esferas: à esfera cultural, o trabalho demanda de um elemento de significação que atue como um roteiro de ação, já que um agir puramente mecânico, transitivo, automático, perderia a especificidade humana. A atividade produtiva, da mais simples à mais sofisticada, sustenta-se numa configuração técnica que tem sua gênese na intencionalidade de um projeto. Além disso, a intervenção sobre mundo natural supõe um investimento coletivo, um esforço conjunto, dados os desdobramentos da divisão técnica do trabalho em sua divisão social. A produção dos bens naturais, à vista da destinação e das características da natureza, só pode realizar-se integralmente no contexto social.

Por sua vez, a atividade cultural, em que pese sua aparência de configuração subjetiva autônoma, só se realiza na dependência das condições da vivência de uma coletividade e numa base material; ela depende da saúde orgânica dos corpos, decorrente de uma relação fecunda com o mundo, e do intercâmbio dos bens simbólicos do contexto cultural, que atua como uma autêntica placenta para os atos simbólicos. Disso decorre que não há cultura subjetiva se não houver um lastro de cultura objetivada.

Finalmente, a própria vida social, o convívio humano, pressupõe tanto essa infraestrutura material do habitat natural - tecido pelo manejo das relações com a natureza - como a malha de significações disponibilizadas pela cultura. Sem esta última, a vida humana não seria social, mais puramente gregária.

Assim, o existir humano histórico se realiza mediante práticas concretas agregadas entre si, de forma dialeticamente complexa; desdobra-se então numa tríplice esfera, formando uma totalidade 
integrada em que cada parte guarda sua especificidade, ao mesmo tempo que depende das outras duas. Trabalho, sociabilidade e cultura são três faces de uma mesma realidade: a realidade da existência histórica da humanidade.

\section{A educação como mediação da prática histórica}

É nesse contexto que se pode entender a educação como prática humana. Como tal, ela é simultaneamente uma atividade técnica, uma atividade social e uma atividade cultural. Ela perpassa as três esferas da prática humana geral. Trata-se, pois, de uma modalidade de trabalho, de uma forma de relacionamento social e de uma prática simbólica. Como atividade de trabalho, ela envolve o investimento da energia do homem que opera a transformação da natureza, no caso, intervindo sobre as próprias pessoas em sua condição de seres naturais, sociais e culturais.

Como atividade social, por ser uma prática de intervenção coletiva, é fundamentalmente uma experiência de convívio e de interação de pessoas, uma atividade fundamental do grupo humano.

Mas ela é ainda atividade cultural, por exercer-se prioritariamente com conceitos e valores, que são essencialmente produtos simbólicos.

Mas qual é a sua especificidade e o que lhe dá legitimação? Certamente, a principal condição que a especifica é a sua função de prática mediadora das praticas existenciais básicas, ou seja, a prática educativa se legitima exatamente por ter como finalidade a inserção das pessoas na tríplice esfera do trabalho, da sociabilidade e da cultura. A sua razão de ser encontra-se na sua própria destinação.

É devido a essa total impregnação da educação no tecido da vida social da humanidade que ela precisa ser preocupação central dos seus gestores. Ela se torna uma preocupação universal.

\section{A contribuição da Filosofia da Educação}

É aí que entra a contribuição da Filosofia: subsidiar os sujeitos envolvidos na educação no desvendamento de seu sentido. ${ }^{1}$ Pois a Filosofia da Educação se dá como atividade teórica de desvendamento/construção do sentido da educação no contexto do sentido da existência humana. E, nessa busca de significações, desempenha uma tríplice tarefa.

\section{Buscando os valores da prática educativa}

${ }^{1}$ Uma abordagem mais desenvolvida e aprofundada dessa temática encontra-se no meu livro Educação, sujeito e história (2001), de onde retomo a análise da relação da educação com a prática histórica dos homens, bem como da natureza e do papel da Filosofia da Educação.

Em primeiro lugar, cabe-lhe uma tarefa axiológica. Entram em cena os valores que envolvem a educação na sua condição de prática real. São os valores éticos, estéticos e políticos.

Nessa perspectiva, a Filosofia da Educação é entendida como uma reflexão sobre os fins da atividade educativa, fins estes que se lastreiam 
em valores. Caberia então à Filosofia da Educação explicitar os valores éticos, políticos, estéticos e culturais que pudessem "nortear" a prática educacional. A reflexão filosófica se faria então reflexão axiológica, perquirindo a dimensão valorativa da consciência e a expressão do agir humano na medida em que é relacionado com valores. Sua questão central desta perspectiva axiológica é aquela dos fins da educação, a questão do educar para que.

Mas esta perquirição não pode ser entendida como mera elucidação de valores e fins assumidos por uma sociedade particular. Embora nascendo num contexto singular de uma sociedade e de uma cultura, condição que não pode perder de vista, a indagação sobre os valores éticos se coloca numa perspectiva abrangente de universalidade, referente à condição humana em geral.

Por isso mesmo, a Filosofia da Educação busca explicitar valores para a condução da prática educacional apoiando-se numa antropologia fundada em mediações histórico-sociais, dimensões estas que qualificam e especificam a condição de existência real dos homens. Tal perspectiva nega, retoma e supera aqueles aspectos enfatizados pelas abordagens essencialista e naturalista que se fundam em princípios ontológicos, abstratamente configurados, transcendentes à condição histórica concreta da realidade humana.

Os valores aos quais se vincula a educação desdobram-se num amplo leque de expressões, tal a multiplicidade dos aspectos que a condição humana manifesta na sua abrangente abertura para a ação. Tendo em vista a educabilidade do homem, a ação educativa que nela se funda precisa sensibilizar-se a todos esses valores. Articular o agir a valores é reconhecer neles uma referência para qualificar esse agir, para direcioná-lo à maior humanização do homem. Por isso, não são apenas os valores éticos e políticos - que qualificam as ações mais diretas dos sujeitos humanos - que precisam ser levados em consideração. Assim, os valores estéticos são aqueles que traduzem a sensibilidade à condição corpórea do ser humano como organismo vivo, condição que, se violada, atinge a dignidade do agente. Igualmente, os valores culturais dão testemunho da solidariedade que tece a espécie humana como constituída por seres que doam sentidos diferenciados e específicos a todas as dimensões de seu existir, expressando a intencionalidade que atribui ao mundo e a si mesma.

\section{Construindo a imagem do homem}

Em segundo lugar, cabe-lhe uma tarefa ontológica, pela qual deve buscar o fundamento desses valores. A Filosofia da Educação precisa pensar a condição humana para encontrar aí o fundamento da própria atividade valorativa. Assim, cabe-lhe a construção de uma imagem do homem como sujeito fundamental envolvido na educação. Trata-se de delinear o sentido mais concreto da existência humana com relação às suas coordenadas de educabilidade. Como tal, a Filosofia da Educação 
constitui-se como uma antropologia filosófica, entendida como tentativa de construção de uma visão integrada do ser humano. Trata-se de uma antropologia a ser construída, não mais daquela antropologia metafísica, fundada numa essência humana prefigurada, da qual se deduziriam as referências para o agir, nem de uma antropologia naturalista, de acordo com a qual o homem se reduziria a sua condição de mero organismo biológico.

\section{Explicitando o alcance do conhecimento no campo da educação}

Em terceiro lugar, a Filosofia da Educação precisa tematizar o próprio processo do conhecimento quando implicado na compreensão teórica e na prática histórica da educação como atividade psicossocial. Esta é sua tarefa epistemológica. Nesse seu momento epistemológico, a Filosofia da Educação investe, pois, no esclarecimento das relações entre a produção do conhecimento e o processo da educação. Por isso, cabe-lhe enfrentar um espectro bem amplo de questões nesse plano da produção do saber, desde aquelas relacionadas com a natureza da própria subjetividade até aquelas que se encontram implicadas no mais modesto ato de ensino ou de aprendizagem, passando pela questão da possibilidade e da efetividade da ciência da educação. Com efeito, estão em pauta os esforços que têm sido desenvolvidos com vista à criação de um sistema de saber no campo da educação, de tal modo que se possa dispor de um corpo de conhecimentos fundados numa episteme, num saber rigoroso e consistente. Trata-se da questão da cientificidade para o campo educacional.

Mas integra ainda o espaço epistemológico da Filosofia da Educação a crítica aos enviesamentos ideológicos que se insinuam permanentemente nos âmbitos da teoria e da prática educacionais. Lidando prioritariamente com ferramentas da subjetividade, com conceitos e valores, a educação é terreno fértil para a ideologia, que particulariza princípios e valores universais.

À luz dessas referências gerais, tem-se que são consideradas temáticas de interesse específico da Filosofia da Educação aquelas relacionadas aos valores implicados na prática educativa, aos processos do conhecimento no campo educacional e à própria realidade existencial do homem na sua condição de educabilidade.

No equacionamento dos valores que presidem a prática educativa, legitimando suas finalidades e objetivos, afluem os valores éticos, valores estéticos, valores políticos e, em suma, valores culturais.

Na busca da imagem histórica real e concreta do existir humano, a Filosofia da Educação se socorre da valiosa contribuição analítica que lhe disponibilizam hoje as Ciências Humanas. Essa parceria contribui significativamente para que ele evite os declives traiçoeiros de um pensar idealista e abstrato.

Já na descrição e na crítica dos processos epistêmicos envolvidos na educação, a Filosofia da Educação fica atenta aos caminhos do exercício rigoroso da subjetividade e aos riscos do enviesamento ideológico. 
Pauta assim, como temática fundamental, a própria possibilidade do conhecimento científico no campo educacional.

\section{A presença da Filosofia da Educação nos trabalhos publicados na Rbep}

A produção filosófica registrada nas páginas da Revista nos últimos 15 anos se distribuiu de forma aleatória, tanto na dimensão cronológica como na perspectiva das temáticas abordadas. Foram identificados 23 trabalhos que abordaram e discutiram temáticas filosóficas.

Para fazer o presente balanço, foram colocadas as seguintes questões: Que temas são priorizados? Que problemas são colocados? Que referências paradigmáticas são privilegiadas? Que balanço fazer?

Sob a perspectiva das temáticas trabalhadas, os textos puderam ser distribuídos nas seguintes categorias: textos que abordam as questões ligadas à prática educativa, particularmente nos âmbitos da ética e da política; textos relacionados à estética na educação; textos versando sobre o sentido geral da educação enquanto mediação da formação humana.

\section{Refletindo sobre os valores que fundamentam a prática educativa}

\section{A ética na prática educativa}

A discussão sobre a fundamentação da ética e da moralidade, bem como sua gênese e manifestação, aparece em três artigos.

Em "Moralidade, ética, autonomia e educação" (1997, p. 216-235), Luzia Marta Bellini e Adriano Rodrigues Ruiz, tomando aportes piagetianos acerca da inteligência prática e da construção da moral, defendem que a educação escolar tem como objetivos a autonomia moral e intelectual dos sujeitos como garantia da construção de relações éticas direcionadas para a cooperação e para a solidariedade, bases imprescindíveis para a prática da cidadania no contexto social. As autoras refletem sobre a moralidade com base nas representações de alunos adultos de um Projeto de Alfabetização.

Já Renê José Trentin Silveira, em "Ética como tema transversal" (2009, p. 695-709), reflete sobre a natureza da ética e sua relação com a dimensão política da cidadania, mas sob a perspectiva de sua ensinabilidade. Discute então a transversalidade de seu ensino, conforme proposto pelos Parâmetros Curriculares Nacionais (PCN). Destaca a fragilidade dos argumentos apresentados pelos defensores dessa vida pedagógica com base nos supostos epistemológicos do próprio conhecer e do aprender, desvendando posições ideológicas que se imiscuem nessa forma de conceber a formação ético-politica dos adolescentes. Entendendo a ética como pensamento ou reflexão sobre os valores e as normas que norteiam as condutas dos homens na sociedade, destaca a 
historicidade dos dilemas éticos e das respostas que lhes são dadas ao longo da temporalidade histórica.

Fazendo uma íntima articulação entre as esferas ética e política, o trabalho de Maria Augusta Salin Gonçalves e Orene Maria Piovesan, "Processo de construção de normas na escola e formação para a cidadania" (2006, p. 210-219), partindo de resultados de pesquisa-ação em escola de ensino fundamental marcada por conflitos correntes, discorre sobre as potencialidades do diálogo para assegurar a participação de todos os segmentos da escola na construção de normas com vista a um relacionamento pautado na cidadania. As autoras têm como perspectiva a aquisição de saberes éticos e de ações educativas relacionados ao desenvolvimento da consciência moral que possa dar sustentação na lida com os conflitos recorrentes na interação social. O diálogo sobre a criação de normas no contexto do intercâmbio pedagógico, sobretudo envolvendo toda a comunidade escolar (pais, funcionários, professores e alunos), transforma a escola em lugar de formação para a cidadania. A conclusão é de que essa formação será alcançada mediante o diálogo autêntico se conduzido sem as estratégias de coerção gerada pelas relações do poder. Pode emergir assim uma nova racionalidade, aval para a construção de uma nova convivência social.

\section{Os valores políticos da educação}

As implicações da educação com os valores especificamente políticos são trabalhadas em vários artigos.

José Sérgio F. de Carvalho, em "O declínio do sentido público da educação" (2008, p. 411-424), reportando-se a Hannah Arendt, destaca o esvanecimento do ideal ético-político da educação devido à diluição das fronteiras entre a esfera pública e a esfera privada. Compromete-se então o ideal maior sempre almejado pela educação, que era a participação de um mundo comum e público, para limitar-se à obtenção de competências e habilidades para a produção para o lucro e o consumo; todas as demais esferas da ação laborativa são sufocadas por essa finalidade consumista. Supremacia do labor, da produtividade e do consumo nas metas educacionais esvazia por completo o investimento na formação do cidadão. Opera-se então a substituição do sentido público e político da formação, tal como pleiteado pela tradição humanista que se fizera matriz e princípio dos ideais republicanos, por seu valor de mercado. Não se compartilha mais uma herança cultural pública, mas um capital cultural privado. Os valores culturais passam a ser tratados como meros valores de troca, perdendo toda sua destinação de formadores de sujeitos cidadãos.

A intensa interpelação dos valores políticos pela educação é explicitada por Neiva Afonso Oliveira, Gumercindo Ghiggi e Avelino da Rosa Oliveira, em "A pedagogia política de Rousseau: formação pela experiência livre e pela autoridade da vontade geral" (2008, p. 341-351), quando fazem uma retomada dos conceitos de experiência, liberdade e 
vontade geral como sustentáculos da pedagogia política. Esta tem como elemento central a explicitação da natureza do poder político. À luz de seus princípios antropológicos, Rousseau subsidia a compreensão do processo educativo discutindo a tensão entre a liberdade e a autoridade, tensão que o homem, vocacionado à humanidade, enfrenta para realizar sua própria formação. Já se faz então presente na filosofia educacional de Rousseau a importância da experiência a ser vivida pelo educando, cabendo ao educador apenas acompanhá-lo. O que prevalece é, então, o exercício da liberdade bem regrada. A intervenção do educador deve direcionar-se a consolidar a liberdade do educando, que deve ater-se tão somente à autoridade soberana da vontade geral, substrato comum dos homens livres.

Não é diferente a proposta educativa de Paulo Freire, em que a autonomia dos sujeitos históricos é visada fundamental, sejam eles os educandos ou os educadores, que, para tanto, precisam ser igualmente formados. Vão nessa direção as análises e reflexões de Ana Maria Saul e Antonio Fernando Gouvêa Silva em "O legado de Paulo Freire para as políticas de currículo e para a formação de educadores no Brasil" (2009, p. 223-244). Ao discutir propostas de gestão de Paulo Freire à frente da Secretaria da Educação de São Paulo, os autores destacam a marca de um paradigma curricular de racionalidade crítico-emacipatória e de um modelo de formação de professores coerentes com os pressupostos filosóficos que sustentaram seu pensamento educacional. O legado de Paulo Freire se expressa como uma matriz importante a inspirar tanto a teoria como a prática de todos os que assumem compromisso com uma educação democrática, à busca de um projeto social fundado na ética do ser humano e em princípios de justiça social e de solidariedade.

Manuel Gonçalves Barbosa, em seu artigo "Educação e imaginário intercultural: recomposição do papel da sociedade civil" (2011, p. 477492), partindo da situação modificada das atuais sociedades europeias, propõe vincular a educação a uma lógica inclusiva da democracia ante a reconfiguração das sociedades pela multiculturalidade que se impõe pela diversidade dos povos que as constituem na atualidade. Retoma o tema do destino político da educação em face das mudadas configurações da sociedade contemporânea, profundamente marcada pela interculturalidade decorrente da diversidade dos povos que a constituem. Um novo cenário se configura para o desempenho da sociedade civil no que concerne a seu protagonismo educativo, no sentido de implementar a interculturalidade e a convivialidade, recompondo assim o seu papel educativo, com cultivo sistemático da virtude da civilidade - entendida como tratamento dos demais como iguais - e de disposição para a interação dialogante e o convívio com a alteridade cultural. Uma educação dos sentimentos e uma reconversão dos afetos se fazem necessárias. O que se impõe é um olhar cosmopolita, forma de encarar o outro sem por ênfase essencialista na diferença e sem dissolvê-la no céu estrelado do universalismo abstrato, não criando um abismo entre o que é estranho e o que é familiar.

Ao retomar o histórico da reforma educacional do Rio Grande do Sul, Claudemir de Quadros, no seu artigo "Lourenço Filho: reformador da 
educação no Rio Grande do Sul" (2009, p. 204-222), enseja uma reflexão sobre a modernização da educação nacional a partir de uma inspiração filosófica e doutrinária sustentada em bases técnicas e científicas. Trata-se de exemplo do impacto que o ideário escolanovista provoca nas iniciativas do Estado republicano para a instauração do sistema público de ensino no País, marcando assim sua política educacional.

\section{A dimensão estética do educar}

Sem dúvida, Dewey tem contribuição significativa, no âmbito da Filosofia da Educação, ao chamar a atenção para o papel da sensibilidade estética, ao explicitar o lugar da arte na educação. Entende a arte como experiência intensa e inteligente, compreendendo a atividade do pensamento imaginativo na recriação de reordenação de significados vivenciados. Mas a experiência assim redimensionada, envolvendo o lúdico e o estético, é privilegiada para a convivência social, assegurando a continuidade entre o individuo e seu meio social - é ela que dá à educação o seu caráter democratizante. Tal a apresentação que Cecília Maria Siqueira Silva faz em "A dimensão estética e democrática da experiência: uma contribuição da filosofia deweyana para novas propostas educacionais" (2006, p. 360-369).

A presença de Dewey na reflexão brasileira sobre a educação é bastante marcante, tendo merecido a atenção do artigo de Marcus Vinicius da Cunha e Débora Cristina Garcia "A apropriação de John Dewey na Revista Brasileira de Estudos Pedagógicos (1944-1964)" (2009, p. 176-203). Mostram os autores que a apropriação de Dewey na Rbep se deu por três vias, conforme os aspectos que são enfatizados: políticos, filosóficos ou pedagógicos. A partir de levantamento e de análise de 88 artigos que se referem de algum modo ao pensamento de Dewey, os autores identificam essas vias de apoio sob as quais se dá essa apropriação, levando em conta a natureza dos elementos rastreados e a destinação que se lhes propõe. Assim, configura-se o amplo painel das inspirações deweyanas em nosso meio, pela amostra constituída com as matérias publicadas nesta Revista. Do ponto de vista filosófico, o elemento fundamental é de natureza epistemológica, explicitando-se a noção de experiência como o princípio norteador do filósofo; do ponto de vista político, o destaque fica para o caráter socializador da escola, onde os educandos devem incorporar hábitos democráticos para viverem em sociedade, contribuindo para uma mudança que assegure seu constante aprimoramento; do ponto de vista pedagógico, pensa a ação educativa respaldada nesses princípios, sendo desenvolvida pelo estímulo ao educando para a construção de sua autonomia.

\section{A perspectiva epistemológica do saber em educação}

Já a reflexão e o debate sobre os aspectos epistemológicos do conhecimento e suas relações com a educação se expressam em outros 
tantos artigos, revelando a preocupação com o campo epistêmico, discutindo a possibilidade de um saber científico na área.

No artigo "A relação educação, ciência e interdisciplinaridade" (2000, p. 403-414), Gildemarks Costa Silva põe em pauta a constituição de uma teoria pedagógica à altura das teorias das demais áreas, propondo-se uma perspectiva interdisciplinar para a ciência da educação, defendendo a autonomia relativa do campo pedagógico. O problema debatido é o da cientificidade possível de uma abordagem que tenha o educacional como objeto de conhecimento científico. Entende o autor que, até para se desenvolver de maneira interdisciplinar, esse conhecimento precisa se afirmar em sua autonomia disciplinar.

Igualmente, situando-se no âmbito epistemológico, em diálogo com Perelman, Renato José de Oliveira, em "O problema da verdade e a educação" (2005, p. 55-63), discute a possibilidade do conhecimento da verdade, na perspectiva de se avaliar sua solidez como fundamento do próprio conhecer e do agir moralmente válido. Trata do estatuto do conceito de verdade na filosofia contemporânea. Desse modo, tanto a ética em geral como a educação em particular têm suas bases estremecidas, uma vez que precisam lidar com um saber sempre provisório, contando com um conhecimento apenas confiável e não mais absoluto. Como atividade comum do homem, empresa verdadeiramente humana, sem nenhum respaldo de uma inteligência ou de uma vontade transcendentes, o conhecimento se marca por radical e necessária contingência.

Liliana Soares Ferreira, em "Pedagogia como ciência da educação: retomando uma discussão necessária" (2010, p. 233-251), traz argumentos que confirmam a pedagogia como ciência da educação, com sua especificidade, ao incluir sujeitos e ações, levando em conta a linguagem, a subjetividade e a historicidade da educação. Apoiando-se em Saviani, defende o estatuto de ciência para a pedagogia, uma vez que se trata de empreendimento epistêmico capaz de gerar teoria, uma teoria da educação, teoria que se estrutura a partir e em função da prática educativa. Distingue-se assim daquelas outras teorias da educação que analisam a educação nas suas relações funcionais com a sociedade.

\section{A Filosofia da Educação pensando a natureza do processo educacional}

A Filosofia da Educação deixa sua marca nas páginas da Revista, no período em análise, também quando tematiza e debate a natureza do processo educacional em si mesmo. Momentos de busca do significado da educação como formação do humano, quando voltada seja para a construção do sujeito pessoa individual, seja para a constituição da comunidade social. Sempre em vista uma intervenção que acompanha e fecunda o devir dos homens buscando uma constante mudança rumo a um completar-se de seu modo de ser.

É o que se encontra no artigo de Maurício Mogilka "O homem e sua formação integral" (2006, p. 53-67). Também se referindo a Rousseau, 
Dewey e Roger, discute o sentido do próprio processo da educação, que entende então como formação integral do homem. A integralidade da formação é vista como requisito não só da construção da autonomia do sujeito, mas também da preparação para a cidadania, da educação democrática, uma vez que os processos não democráticos decorrem sempre de situações de subjetividade fragmentada.

Também Ormezinda Maria Ribeiro, em "E se Narciso conhecesse Alice? Conjeturas a respeito de um tema da educação" (2006, p. 44-52), jogando com as mensagens do mito de Narciso e do conto de Alice no país das maravilhas, propõe outra forma de se compreender o sentido da educação. Também aqui está ocorrendo a reflexão sobre a natureza do processo educacional. Trabalhando numa alegoria metafórica, busca entender como funciona a educação, concluindo que é preciso adotar a atitude de Alice, superando o narcisismo vigente.

Na mesma direção vão as considerações feitas por Martha D'Angelo, em "Filosofia e educação em Walter Benjamin" (2006, p. 68-75): trata-se da exploração dos conceitos filosóficos de Walter Benjamin e da sua fecundidade para se pensar a educação - trabalha sua grande contribuição para a Filosofia da Educação. A autora destaca a contribuição que está na riqueza que Benjamin atribui ao potencial formativo da experiência autêntica possível ao se resgatar o passado oprimido, ao demandar o esforço da memória para enfrentar os acontecimentos traumáticos da barbárie humana. A educação tem também seus monumentos de barbárie a serem enfrentados. Ela não pode se contentar a ser intuição geradora e legitimadora desses monumentos de cultura. Daí vem a contribuição benjaminiana para a educação emancipadora, com seu estímulo a que a educação seja arrancada de seus nichos institucionais e caia no mundo da vida real. Tarefa sem dúvida difícil, envolvendo uma revisão completa das práticas da educação, a ser feita por uma escovação, a contrapelo, da história da educação.

O processo educativo está também na berlinda no artigo de Valeska Zanello "Filosofia, psicanálise e educação: o 'mestre possível' de adolescentes" (2007, p. 171-176), agora sob as luzes desvendadoras da Psicanálise. Ao discutir a formação que se espera fecunda, presente no ensino de Filosofia para crianças, a autora chama a atenção para o mesmo investimento na formação dos professores, pois o professor-formador não pode atuar como mestre todo-poderoso e onisciente. A educação só poderá ser emancipatória se a intervenção docente se desinvestir do lugar do saber total. É preciso, para que seja fértil, que ela se abra para o saber e para a fala do aluno.

Antonio Zuin, em "A dialética socrática como paideia irônica" (2008, p. 11-29), atualiza o potencial pedagógico da ironia socrática, que aborda chamando Zaratrusta ao diálogo. Ela gera novos significados ao desmascarar a arrogância do dogmático senso comum. Volta à tona a dialética que vincula a autoridade do mestre e a liberdade do discípulo. A autoridade do mestre, quando ciente de suas forças, mas, também, de suas limitações, é fecunda para a formação do discípulo, por saber que sua superioridade é 
contingencial, pois traz em si sua superação, que não significa, no entanto, sua eliminação, já que a intervenção do mestre se conserva, modificada, no raciocínio construído pelo discípulo, que, por sua vez, se sente respeitado como partícipe do processo de ensino/aprendizagem. Na proposta e na prática educativa de Sócrates se faz presente a amizade, como ambiente afetivo da relação pedagógica.

Rita Pimenta, em "O que complementa uma poética do ensino? Uma retórica do ensino" (2008, p. 232-241), trabalha a articulação necessária entre a poética do ensino e a retórica do ensino - poética do ensino tal como concebida por David Hansen, que resgata a categoria aristotélica de retórica. Defende que a poética do ensino precisa se completar com a retórica. A poética do ensino é vista como o conjunto processual dos discursos ético, estético e intelectual. A discursividade é o substrato, sendo que o discurso possibilita aos envolvidos no processo ensino/aprendizagem o aflorar das emoções, mobilizar ações, bem como conhecimentos prováveis, que abrem espaço para o debate científico.

O tema da autonomia, para a qual se deve direcionar a educação, reaparece no texto de Manuel Gonçalves Barbosa "Do sonho ao pesadelo: a pedagogia da autonomia sob suspeita" (2008, p. 455-466). O tema agora é colocado nas coordenadas do cenário histórico-social da atualidade: do sonho rousseauniano ao pesadelo do impacto do ideário neoliberal, onde só resta a autossuficiência do indivíduo, com o comprometimento da autonomia autêntica. Mas a pedagogia da autonomia continua sendo horizonte imprescindível de toda educação, uma vez que constitui direito de todos o enriquecimento de seu potencial humano de autodeterminação e de autoestima no seio da sociedade. Ainda há lugar para ela devido ao seu objetivo, qual seja, o empowerment de cada um.

Para Alberto Filipe Ribeiro de Abreu Araujo, em "Quando o imaginário se diz educacional" (2010, p. 679-705), o imaginário educacional, lugar das imagens que povoam a mente humana (símbolos, mitos, metáforas, alegorias, ideologemas), tem como sua base o tema da formação. Mas nos embates da cultura cotidiana ele se apresenta como um imaginário degradado, uma vez que acaba sendo transposto para um discurso reconceptualizado e consequentemente empobrecido do ponto de vista mítico-simbólico, daí a necessidade de uma hermenêutica adequada para sua decifração - é o que propõe a mitanálise. Essa hermenêutica, como ato interpretativo, busca restaurar o sentido existencial veiculado pela tradição das grandes imagens simbólicas. A educação, lugar de encontro de mestres e discípulos, precisa então cultivar uma racionalidade crítica imaginativa e uma imaginação dotada de olhar crítico. A formação humana, a se esperar da educação, será sempre um permanente equilíbrio entre razão e sensibilidade.

Sergio Pereira da Silva, em "Pedagogia do ressentimento: o otimismo nas concepções e nas práticas de ensino" (2011, p. 107-125), a partir de Nietzsche e de Marx, trabalha a Pedagogia do Ressentimento, gerada pelo otimismo pedagógico. O pessimismo pedagógico é seu antídoto e estratégia de superação dessa pedagogia. Desenvolve sua reflexão tendo por 
pano de fundo o sonho e a promessa de uma educação que se constitua como uma paideia trágica, dionisíaca, que produza homens e mulheres livres, aguerridos, competentes e compromissados com os desafios.

Na verdade, o que está em pauta é uma concepção da educação em que o otimismo pedagógico não represente uma estratégia lógica e covarde de fuga ao sofrimento da vida. Um pessimismo dionisíaco que se torne redentor do espírito trágico. Uma educação que diga sim à vida, que una o otimismo marxista ao pessimismo trágico nietzscheano.

\section{Considerações finais}

Obviamente, a breve retomada que foi feita dos artigos publicados nos últimos 15 anos da Revista não pretendeu dar conta da concepção filosófico-educacional subjacente ao seu projeto editorial. Teve a intenção tão somente de apresentar como a reflexão filosófica se manifestou, em suas páginas, nesse curto espaço de tempo. São várias as perspectivas pelas quais se pode apreender a presença da Filosofia da Educação nas mais diferentes modalidades dos discursos que se pronunciam sobre a educação. ${ }^{2}$

Com efeito, pressupondo que o filosofar se dá mediante uma reflexão sistemática sobre a realidade, de forma totalizante, entendo a Filosofia da Educação como reflexão que discute e questiona o todo da educação. Muito embora essa reflexão possa ser feita tomando em consideração aspectos parciais, formulando questões setoriais, o objetivo é sempre o de se entender o todo da educação no contexto da totalidade da existência real dos homens. Desse modo, desenvolvem uma reflexão típica da Filosofia da Educação aqueles pensadores, teóricos ou práticos, que, para implementarem suas teorias ou ações, constituem um contexto reflexivo abrangente, elaborando uma concepção da educação como um todo.

Assim, a Filosofia da Educação pode estar se manifestando de forma explícita num discurso sistematizado específico sobre a educação. Com efeito, o lugar, por assim dizer, natural, da expressão da Filosofia da Educação é o do discurso elaborado por aqueles pensadores que pretendem construir uma teoria filosófica explícita sobre a educação, tal como é feito por pessoas ou grupos que assumem intencionalmente a educação como objeto de estudo e de reflexão.

Por outro lado, é possível identificar a presença de uma significação filosófica da educação implícita numa elaboração puramente filosófica, ou seja, toda construção teórica de cunho filosófico traz embutida em si uma concepção de educação, assim como de política, que necessita de uma mediação filosófica para se consolidar, uma vez que se trata de duas dimensões intrínsecas da prática real dos homens, que não podem deixar de integrar uma visão filosófica da realidade, seja num âmbito epistemo-

${ }^{2}$ Estas últimas considerações retomam ideias já trabalhadas em texto anteriormente publicado (Severino, 1999). lógico, axiológico ou ontológico. Assim, colocando-se do ponto de vista da Filosofia, pode-se concluir que a todo sistema filosófico, a toda teoria filosófica, a todo pensamento de um autor do campo filosófico corresponderia 
igualmente uma expressão filosófico-educacional. É por isso que se pode falar da concepção existencialista da filosofia, das decorrências filosófico-educacionais do estruturalismo, etc.

Mas é sempre possível identificar ainda uma significação filosófico-educacional como pressuposta nas práticas pedagógicas e nas teorias educacionais sob a forma de referência paradigmática filosófico-educacional. Com efeito, todas as dimensões e processos de educação, ao se realizarem e para ganharem sua significação educativa, remetem-se a referências significativas fundantes, no âmbito filosófico-educacional. Trata-se de uma significação subjacente, pressuposta, latente. Nesse sentido, todo ato educacional, toda prática educacional, toda proposta técnico-pedagógica, toda disciplina, todo campo teórico científico embutiria uma concepção filosófica da educação.

No caso deste artigo, o caminho seguido foi o primeiro, já que se tratou tão somente de retomar, de forma sintética, as abordagens nas quais a intenção dos autores era a de configurar um filosofar explícito sobre a educação. Resta-me esperar que ele tenha conseguido dar conta da tarefa.

\section{Referências bibliográficas}

ARAUJO, Alberto F. R. de A. Quando o imaginário se diz educacional. Revista Brasileira de Estudos Pedagógicos, Brasília, v. 91, n. 229, p. 679-705, set./dez. 2010.

BARBOSA, Manuel Gonçalves. Do sonho ao pesadelo: a pedagogia da autonomia sob suspeita. Revista Brasileira de Estudos Pedagógicos, Brasília, v. 89, n. 223, p. 455-466, set./dez. 2008.

Educação e imaginário intercultural: recomposição do papel da sociedade civil. Revista Brasileira de Estudos Pedagógicos, Brasília, v. 92, n. 232, p. 477-492, set./dez. 2011.

BELLINI, Luzia M.; RUIZ, Adriano R. Moralidade, ética, autonomia e educação. Revista Brasileira de Estudos Pedagógicos, Brasília, v. 78, n. 188-190, jan./dez. 1997.

CARVALHO, José Sérgio F. de. O declínio do sentido público da educação. Revista Brasileira de Estudos Pedagógicos, Brasília, v. 89, n. 223, p. 411-424, set./dez. 2008.

CUNHA, Marcus V. da; GARCIA, Débora C. A apropriação de John Dewey na Revista Brasileira de Estudos Pedagógicos (1944-1964). Revista Brasileira de Estudos Pedagógicos, Brasília, v. 90, n. 224, p. 176-203, jan./abr. 2009. 
D'ANGELO, Martha. Filosofia e educação em Walter Benjamin. Revista Brasileira de Estudos Pedagógicos, Brasília, v. 87, n. 215, p. 68-75, jan./abr. 2006.

FERREIRA, Liliana Soares. Pedagogia como ciência da educação: retomando uma discussão necessária. Revista Brasileira de Estudos Pedagógicos, Brasília, v. 91, n. 227, p. 233-251, jan./abr. 2010.

GONÇALVES, M. Augusta S.; PIOVESAN, Orene Maria. Processo de construção de normas na escola e formação para a cidadania. Revista Brasileira de Estudos Pedagógicos, Brasília, v. 87, n. 216, p. 210-219, maio/ago. 2006.

LÉVÊQUE, Raphael; BEST, Francine. Por uma filosofia da educação. In: MIALARET, Gaston. Tratado das ciências pedagógicas. São Paulo: Ed. Nacional, 1974.

MOGILKA, Maurício. O homem e sua formação integral. Revista Brasileira de Estudos Pedagógicos, Brasília, v. 87, n. 215, p. 53-67, jan./abr. 2006.

OLIVEIRA, Neiva A.; GHIGGI, Gumercindo; OLIVEIRA, Avelino da R. A pedagogia política de Rousseau: formação pela experiência livre e pela autoridade da vontade geral. Revista Brasileira de Estudos Pedagógicos, Brasília, v. 89, n. 222, p. 341-351, maio/ago. 2008.

OLIVEIRA, Renato J. de. O problema da verdade e a educação. Revista Brasileira de Estudos Pedagógicos, Brasília, v. 86, n. 213-214, p. 55-63, maio/dez. 2005.

PIMENTA, Rita. O que complementa uma poética do ensino? Uma retórica do ensino. Revista Brasileira de Estudos Pedagógicos, Brasília, v. 89, n. 221, p. 232-241, maio/ago. 2008.

QUADROS, Claudemir de. Lourenço Filho: reformador da educação no Rio Grande do Sul. Revista Brasileira de Estudos Pedagógicos, Brasília, v. 90, n. 224, p. 204-222, jan./abr. 2009.

RIBEIRO, Ormezinda M. E se Narciso conhecesse Alice? Conjeturas a respeito de um tema da educação. Revista Brasileira de Estudos Pedagógicos, Brasília, v. 87, n. 215, p. 44-52, jan./abr. 2006.

SAUL, Ana Maria; SILVA, Antonio F. G. O legado de Paulo Freire para as políticas de currículo e para a formação de educadores no Brasil. Revista Brasileira de Estudos Pedagógicos, Brasília, v. 90, n. 224, p. 223-244, jan./abr. 2009. 
SEVERINO, Antônio J. Filosofia da Educação no Brasil: esboço de uma trajetória. In: GHIRALDELLI JR., Paulo. (Org.). O que é Filosofia da Educação? Rio de Janeiro: DP\&A, 1999. p. 267-328.

SILVA, Cecília M. S. A dimensão estética e democrática da experiência: uma contribuição da filosofia deweyana para novas propostas educacionais. Revista Brasileira de Estudos Pedagógicos, Brasília, v. 87, n. 217, p. 360-369, set./dez. 2006.

SILVA, Gildemarks C. A relação educação, ciência e interdisciplinaridade. Revista Brasileira de Estudos Pedagógicos, Brasília, v. 81, n. 199, p. 403-414, set./dez. 2000.

SILVA, Sergio P. da. Pedagogia do ressentimento: o otimismo nas concepções e nas práticas de ensino. Revista Brasileira de Estudos Pedagógicos, Brasília, v. 92, n. 230, p. 107-125, jan./abr. 2011.

SILVEIRA, Renê J. T. Ética como tema transversal. Revista Brasileira de Estudos Pedagógicos, Brasília, v. 90, n. 226, p. 695-709, set./dez. 2009.

ZANELLO, Valeska. Filosofia, psicanálise e educação: o "mestre possível" de adolescentes. Revista Brasileira de Estudos Pedagógicos, Brasília, v. 88, n. 218, p. 171-176, jan./abr. 2007.

ZUIN, Antonio. A dialética socrática como Paideia irônica. Revista Brasileira de Estudos Pedagógicos, Brasília, v. 89, n. 221, p. 11-29, jan./ abr. 2008.

Antonio Joaquim Severino, doutor em Filosofia pela Pontifícia Universidade Católica de São Paulo (PUC-SP) e livre-docente em Filosofia da Educação pela Universidade de São Paulo (USP), é professor titular de Filosofia da Educação, ora aposentado, da Faculdade de Educação dessa Universidade. Atualmente trabalha no Programa de Pós-Graduação em Educação da Universidade Nove de Julho (Uninove), em São Paulo. ajsev@uol.com.br 